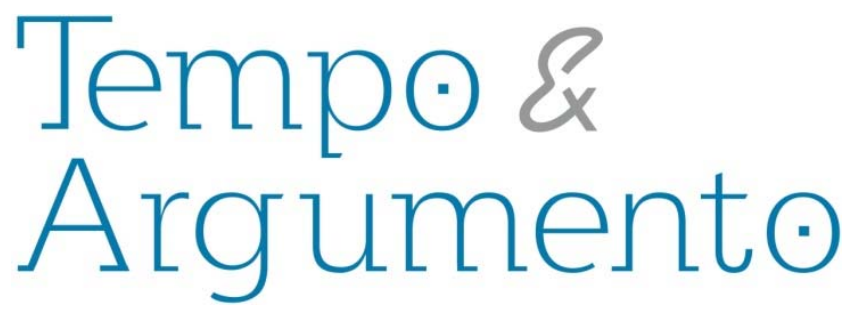

\title{
Historia de las izquierdas colombianas entre 1958 y $2010^{1}$
}

\begin{abstract}
Resumen
Este artículo mira la historia de las izquierdas en Colombia, enmarcada dentro de lo que ocurría en el país, América Latina y el mundo entre 1958 y 2010. Luego de precisar lo que entendemos por "izquierdas" y de trazar los antecedentes de ellas en la primera mitad del siglo XX, se hace un recorrido por cinco grandes momentos del periodo estudiado para llegar a la situación reciente. La cronología privilegia los aspectos internos de la historia de las izquierdas colombianas, lo que permite apreciar los logros y limitaciones de éstas enmarcadas en un contexto particular como es el colombiano.
\end{abstract}

Palabras clave: Colombia; Izquierdas; Guerrillas; Movimientos Sociales.

\author{
Mauricio Archila \\ Doctor y Profesor de Posgrado en la \\ Universidad Nacional de Colombia, Sede \\ Bogotá, e investigador asociado del Centro de \\ Investigación y Educación Popular (CINEP). \\ Colombia. \\ marchilan@gmail.com
}

\section{Jorge Cote}

Estudiante de Maestría en Historia en la Universidad Nacional, sede Bogotá.

colombia.

koterpy@gmail.com

\section{Para citar este artículo:}

ARCHILA, Mauricio; COTE, Jorge. Historia de las izquierdas colombianas entre 1958 y 2010. Tempo e Argumento, Florianópolis, v. 7, n.16, p. 81 - 107. set./dez. 2015.

\section{DOI: $10.5965 / 2175180307162015081$}

http://dx.doi.org/10.5965/21751803071652015081

\footnotetext{
${ }^{1}$ La propuesta cronológica de este artículo apareció en Archila y otros (2009). Para esta nueva publicación, se hicieron ajustes de forma y se ampliaron los antecendentes de la izquierda colombiana de la primera mitad del siglo XX, así como de sus etapas iniciales e igualmente al final se ofrecen algunos puntos sobre la situación actual. También se redujeron sustancialmente las consideraciones internacionales. Es, pues, un artículo de síntesis que recoge parte de nuestra producción previa y de una actualizada literatura secundaria sobre el tema.
} 


\section{History of the Colombian left-wings between 1958 and 2010}

\begin{abstract}
This article looks at the left colombian history, within the framework taking place in the country, in Latin America, and in the world between 1958 and 2010. Just after specifying what we mean by left and outlining their antecedents in the first half of the 2oth century, a tour is taken through five great moments within the period under study to reach the recent situation. The chronology favors internal aspects of the left Colombian history, and this allows estimating their achievements and limitations framed within a particular context such as the Colombian one.
\end{abstract}

Keywords: Colombia; Left-wings; Guerrillas; Social Movements.

\section{História das esquerdas colombianas entre 1958 e 2010}

\begin{abstract}
Resumo
Este artigo observa a história das esquerdas na Colômbia, contextualizada dentro daquilo que ocorria no país, na América Latina e no mundo entre 1958 e 2010. Logo após especificar o que se entende por "esquerdas" e traçar seus antecedentes na primeira metade do século $X X$, faz-se um percurso por cinco grandes momentos do período estudado para chegar até a situação recente. A cronologia privilegia os aspectos internos da história das esquerdas colombianas, o que possibilita estimar seus êxitos e suas limitações de acordo com um contexto particular como é o colombiano.
\end{abstract}

Palavras-chave: Colômbia; Esquerdas; Guerrilhas; Movimentos Sociais.

Este artículo mira de conjunto la historia de las izquierdas en Colombia, enmarcada dentro de lo que ocurría en el país y el mundo durante la segunda mitad del siglo XX y comienzos del XXI. En otra parte, hemos abordado el problema conceptual de qué es izquierda, al reflexionar sobre su distinción con la derecha (ARCHILA, 2008). Ahora baste decir que son categorías políticas relacionales y no realidades ontológicas, que cambian a lo largo de la historia occidental desde la Revolución Francesa hasta nuestros días. El núcleo de la distinción es la igualdad -opción histórica de la izquierda como lo reconoce 
Bobbio (1995) - balanceada con la libertad. Hoy, la búsqueda de igualdad no se puede entender solo como de clase y menos sin la libertad que la debe acompañar. Es lo que algunos franceses Ilaman ega-liberté (CALLINICOS, 2003) -que traducimos como "equilibertad". En tiempos recientes y especialmente para América Latina, las izquierdas también se caracterizan por el respecto a la diferencia, sea ésta étnica, de género, de orientación sexual o de generación.

Con el objetivo de hacer una narración sobre la historia de las izquierdas en Colombia entre 1958 y 2010, proponemos una periodización que intenta conjugar la evaluación de tres factores: la trayectoria de las organizaciones de izquierda colombiana, la evolución política del país y la historia de la izquierda en el plano mundial y latinoamericano. Por obvias razones, hemos privilegiado el primer criterio, dividiendo la historia de las izquierdas colombianas en seis periodos²:

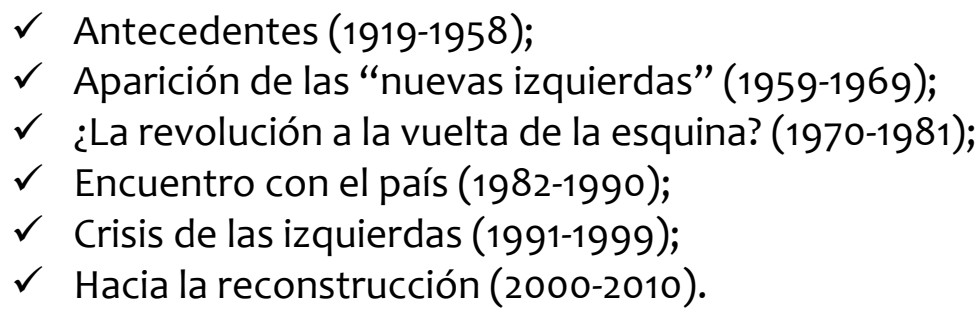

\section{Antecedentes (1919-1958)}

Como el tema central de este artículo son las izquierdas colombianas de la segunda mitad del siglo XX y comienzos del XXI, no nos detendremos en detalle en sus antecedentes remotos. ${ }^{3}$ Aunque en el actual territorio colombiano, desde mediados del siglo XIX, hubo apelaciones a un vago socialismo por parte de intelectuales radicales liberales, éste se va a hacer presente solo hasta la tercera década del XX, debido, entre otros factores, al relativo rezago económico del país, al cierre político conservador desde 1886 y a la existencia de una ideología antisocialista, incluso antes de que este pensamiento adquiriera forma política (MOLINA, 1987).

\footnotetext{
2 En un texto anterior señalábamos, entre 1958 y 1990, seis periodos marcados por la historia política (ARCHILA, 2003, 277-278).

${ }^{3}$ Al respecto, véase Sowell (2006) y Archila (1992).
} 
En efecto, a comienzos de 1919, se reunía en Bogotá una conferencia socialista, que si bien adoptó un programa reformista, presentaba un rostro distinto al del tradicional bipartidismo. ${ }^{4}$ Este temprano socialismo cedió terreno a versiones criollas comunistas y anarquistas, que se expresarían en los congresos obreros de mediados de los 1920, en los que se gestó la Confederación Obrera Nacional (CON), en 1925, y luego el Partido Socialista Revolucionario (PSR), en 1926. Este partido se lanzó a la captación de los primeros núcleos asalariados y, a través de novedosos medios de politización, como las giras de la líder socialista María Cano, puso a temblar a las elites. Ella, y otros dirigentes del PSR, orientaron las grandes huelgas de los enclaves petrolero -octubre de 1927- y bananero -noviembre-diciembre de 1928-, que terminaron en baños de sangre del proletariado, especialmente la última, en la conocida "masacre" de Ciénaga. Estas huelgas hacían parte de la táctica insurreccional adoptada por los socialistas colombianos, en acuerdo con algunos viejos militares liberales, para poner en jaque a la hegemonía conservadora. Pero el país no optó por la insurrección alimentada por la intransigencia derechista, sino por una salida civilista impulsada por los notables liberales que propiciaban la institucionalización del conflicto laboral.

En este cambio de gobierno, también la izquierda se modificó. En agosto de 1930, el PSR fue transformado en un partido de corte bolchevique, según las pautas trazadas por la Unión de Repúblicas Socialistas Soviéticas (URSS). Nació así el Partido Comunista de Colombia (PCC), que en sus primeros años asumió una táctica confrontacional, pero se transformó a mediados de los 1930, por iniciativa de la Internacional Comunista, en una política de alianzas con los sectores progresistas de las burguesías -los Frentes Populares- para frenar el avance del fascismo. Aparecen también por esta época otras expresiones de una izquierda intelectual sin mayor incidencia política. Paralelamente, por un par de años, el dirigente de izquierda liberal, Jorge Eliecer Gaitán, alimentó un grupo político -Unión de Izquierda Revolucionaria (UNIR)- muy cercano al ideario antiimperialista del peruano Haya de la Torre, grupo que se enfrentó crudamente con el PCC, pero luego retornó a las filas liberales.

\footnotetext{
4 Para la trayectoria del socialismo y el comunismo en la primera mitad del siglo XX, véase Medina (1980).
} 
En Colombia, como en otros países de América Latina, al terminar la Segunda Guerra Mundial, se dio una radicalización popular, la que fue respondida con un viraje hacia la derecha impulsado por los Estados Unidos en el marco de la Guerra Fría. En el país, dicho viraje tomó la forma del aislamiento de la izquierda comunista y la derrota del populismo de Jorge Eliécer Gaitán, consumado con su asesinato el 9 de abril de 1948. Este hecho provocó el levantamiento popular conocido como el "bogotazo", que intensificó la confrontación entre los dos partidos tradicionales en la llamada Violencia. Cuando se produjo el cambio del gobierno liberal al conservador, en 1946, el comunismo mantenía la estrategia de Frente Popular en la que gran parte de sus dirigentes adhería al ala moderada del liberalismo. Esta tendencia cambió cuando la dinámica de la Guerra Fría provocó el abandono de la política de Frente Popular en el bloque comunista liderado por la URSS. En consecuencia, el PCC, en su V Congreso, realizado en julio de 1947, reasumió los principios marxistas-leninistas y abandonó las tesis "browderistas" adoptadas a principios de los años 1940.5

En este contexto y ante el aumento de la violencia bipartidista y de la persecución a los miembros del PCC, el comunismo colombiano también inició la discusión sobre la pertinencia del movimiento guerrillero como medio de resistencia (MEDINA, 1980, 598). Para fines de los años 1940, el Partido proclamó la necesidad de formar autodefensas campesinas contra la oleada de violencia oficial. En este sentido, su trabajo en el movimiento armado de estos años consistió en promover algún tipo de coordinación y de unidad de acción entre guerrilleros de influencia liberal o comunista.

Con el ascenso del general Gustavo Rojas Pinilla al poder, en 1953, se ratificó la persecución oficial al PCC, incluso hasta llevarlo a la ilegalidad. Esta situación se mantuvo hasta el año de 1957, cuando, caída la dictadura militar, el Partido apoyó el plebiscito de diciembre de este año para la conformación de la coalición bipartidista llamada Frente Nacional. ${ }^{6}$ Al año siguiente, el PCC ordenó a sus militantes votar por el candidato

\footnotetext{
${ }^{5}$ El browderismo toma el nombre de Earl Browder, dirigente comunista norteamericano, quien al calor de la alianza entre la URSS y EE. UU. durante la Segunda Guerra Mundial habló de la emulación pacífica entre socialismo y capitalismo, la conformación de partidos comunistas de masas y no de cuadros, y el acercamiento a las burguesías nacionales. El PCC adoptó estas ideas en su II Congreso, de 1944, cuando temporalmente cambió su nombre por el de Partido Socialista Democrático (MEDINA, 1980, 529-544).

${ }^{6}$ Este fue un régimen de coalición entre los dos partidos tradicionales para copar en forma paritaria todas
} 
presidencial liberal Alberto Lleras Camargo. Esta decisión causó malestar en algún sector de sus miembros, con lo cual se hicieron más evidentes las tensiones internas que ya se habían manifestado en torno al papel de la lucha armada durante la Violencia.

Al igual que en buena parte del mundo, el predominio del PCC en el escenario de la izquierda colombiana fue una característica de este periodo. Como lo señala Medófilo Medina, el Partido logró en estos años integrar los grupos disidentes, incluido el que en 1947 había arrastrado con buena parte de la militancia obrera (MEDINA, 1980, 599). Es así como durante estos años era prácticamente la única expresión de la izquierda colombiana, pues el Partido Socialista Colombiano, fundado en 1953 por los intelectuales Antonio García y Luis Emiro Valencia, no solo era muy pequeño, sino que se desprestigió por adherir a la dictadura militar. Pero el panorama global y nacional fue modificado por el triunfo de la Revolución Cubana, en enero de 1959, con el que se inaugura un nuevo periodo.

\section{Aparición de las “nuevas izquierdas” (1959-1969)7}

En efecto, el triunfo del movimiento castrista generó grandes expectativas en la izquierda global y especialmente en la latinoamericana, ya que se trataba de una revolución autóctona, al margen de la influencia de la Unión Soviética, comprometida como estaba ésta en la "coexistencia pacífica”. De ahora en adelante, y por mucho tiempo, Cuba se convertiría en el modelo revolucionario por parte de la nueva izquierda latinoamericana, especialmente por la renovación en las formas de lucha que significó el foquismo. ${ }^{8}$

las ramas del Estado y alternarse la presidencia por cuatro periodos (HARTLYN, 1993).

7 El término "nueva izquierda" como tal apareció en Inglaterra con posterioridad a la invasión de Hungría, en 1956. Indignados por este atropello, algunos disidentes se apartan del Partido Comunista Británico y marcan igualmente distancia del laborismo (KAYE, 1989). Por su parte, en Francia surge una disidencia dentro de la izquierda en el contexto de la guerra de liberación de Argelia, entre 1956 y 1962 (TEODORI, 1977, 89-123). La "nueva izquierda" europea se oponía a la burocratización y al reformismo de los "viejos" partidos comunistas y socialistas. Con el tiempo, recibiría influencia de antiguas corrientes anarquistas y trotskistas, así como del novel maoísmo y de ciertos movimientos de liberación nacional asiáticos, africanos y del castrismo o guevarismo.

${ }^{8}$ El foquismo no está muy distante del modelo leninista, pues se trata de vanguardias que aceleran el proceso revolucionario. Claro que en un caso es el partido y actúa en un contexto más urbano, mientras 
En estos años, otro acontecimiento transformó la fisonomía de la izquierda mundial: la ruptura sino-soviética, que se hizo evidente a principios de los años 1960, con la crítica del PC chino al llamado "revisionismo soviético". Este nuevo cisma en el campo comunista significó para la izquierda mundial una mayor pluralización, pero al mismo tiempo nuevos motivos de fragmentación. Junto a los dos acontecimientos anteriormente mencionados, la historia de la izquierda mundial también fue alimentada por la guerra de Vietnam, reiniciada en 1964, debido a la intervención norteamericana, lo que alimentó un sinnúmero de protestas en todo el orbe. Tales eventos se condensaron en el emblemático Mayo del 68 francés, cuando las nuevas izquierdas adquirieron carta de ciudadanía (ELEY, 2003). Sus efectos se sintieron en todas partes del mundo, lo que lo constituyó realmente en un gran movimiento global, incluyendo los países de Europa del Este que buscaron darle un "rostro humano" al socialismo. ${ }^{9}$

Mientras tanto, el marxismo logró difundirse en los medios académicos y universitarios, coadyuvando a la gestación de las ciencias sociales en América Latina. Su influencia tocó incluso sectores del clero que, como Camilo Torres, en Colombia, se radicalizaron hasta tomar las armas. Este diálogo entre cristianismo y marxismo será traducido en la Teología de la Liberación y aplicado por las cada vez más numerosas comunidades eclesiales de base. Paralelamente, brotó una lectura propia del devenir histórico de Latinoamérica conocida como la Teoría de la Dependencia. Al calor de la práctica política de las nuevas izquierdas, surgieron asimismo metodologías investigativas y pedagógicas que darían frutos años después, como las impulsadas por el colombiano Orlando Fals Borda y el brasileño Paulo Freire. Todo ello habla de una renovación teórica en esta parte del mundo, que se nutría de los avances del marxismo occidental, pero dentro de moldes propios (HARNECKER, 2000, 26-30).

en el otro el aparato político-militar se implanta en el mundo rural (DEBRAY, 1975). No sobra señalar que algunos partidos comunistas se lanzaron a la lucha armada, como ocurrió con el venezolano, el guatemalteco y, más adelante, el salvadoreño (MARTí y FIGUEROA, 2006). El colombiano mantenía en este entonces la orientación de autodefensas campesinas, que a mediados de los años 1960 se convirtió en la "combinación de todas las formas de lucha", opción política que sostendrá contra viento y marea hasta tiempos recientes.

9 Esta efervescencia universitaria se sintió también en América Latina. Lo más notorio fue el movimiento estudiantil de México, que tuvo como fecha emblemática la masacre de Tlatelolco, de octubre de 1968 (VOLPI, 2001). 
Colombia no fue ajena a estos cambios continentales y mundiales. Aunque después de la dictadura de Rojas Pinilla, y a diferencia de gran parte de los países latinoamericanos, no conoció ningún régimen militar de facto, el establecimiento del Frente Nacional (1958-1974) alimentó un alto grado de exclusión política y social de las fuerzas no comprometidas con el bipartidismo (HARTLYN, 1993, 105). En este marco de democracia limitada y ante las vacilaciones del PCC se gestan las primeras organizaciones de la nueva izquierda colombiana. ${ }^{10}$

Tal fue el caso del Movimiento Obrero Estudiantil Campesino (MOEC), surgido a raíz de la coyuntura de protesta de principios de 1959 contra el alza del transporte. Al año siguiente, celebró su primer congreso en Cali, la ciudad que más agitación social mostraba en el momento. En un intento apresurado de trasplantar la Revolución Cubana, abrió focos guerrilleros en zonas periféricas, pero con reciente crecimiento económico, en los que murió parte de su dirigencia. Luego se dividió en dos alas: una "izquierdista”, que buscaba el estallido revolucionario inmediato, y la "marxista", que pretendía organizar al pueblo antes de la insurrección. La división se hizo patente cuando se expulsaron mutuamente. Luego se fraccionarían en varios núcleos, uno de los cuales daría origen, años después, al Movimiento Obrero Independiente y Revolucionario (MOIR), uno de los dos grandes partidos maoístas del país.

En efecto, el MOIR fue fundado en Medellín, en 1969, aunque en un principio no se definió si era organización política o aparato sindical. Por ejemplo, en enero de 1970, lanzó la consigna de paro patriótico nacional, pero lo fue posponiendo sin motivo aparente. Nunca se supo si se trataba de una huelga obrera, de un paro cívico o de un movimiento abstencionista. Esta ambigüedad ha sido parte de su comportamiento político. Así, en 1972, se lanzó por primera vez a elecciones, aunque aún no renunciaba al discurso revolucionario, del que se irá apartando hasta convertirse en el sector de izquierda más crítico de la lucha armada. Luego se aliaría con el PCC en un frente

\footnotetext{
${ }^{10}$ En estas páginas retomamos lo escrito en Archila (2003, 278-286).
} 
electoral, para separarse prontamente y continuar su retórica radical, pero con acercamientos a sectores elitistas en pos de construir una burguesía nacional. ${ }^{11}$

Mientras tanto distintas disidencias comunistas dieron orígen a movimientos guerrilleros signados por el foquismo, pero también con tempranas influencias maoístas y luego trotskistas. En 1962, tuvo lugar una conferencia de diversos grupos de izquierda para conformar el Frente Unido de Acción Revolucionaria (FUAR). Convergían allí sectores gaitanistas -entre ellos la hija del caudillo-, socialistas, ex comunistas, del sindicalismo independiente y del movimiento estudiantil. Los unía el común desprecio a la llamada "farsa electoral” y las simpatías por la lucha armada, sin que la desarrollaran en la práctica. Aunque de izquierda, el FUAR no se proclamó marxista. Se fragmentó posteriormente en torno a la definición de las vías de la revolución.

El otro polo significativo de este momento se condensó en el Ejército de Liberación Nacional (ELN) (MEDINA, 1996). Con una mirada autocrítica de las primeras aventuras guerrilleras, un grupo de jóvenes radicales liberales que había viajado a Cuba, se comprometió desde allí a adelantar la revolución armada. ${ }^{12}$ El ELN hizo aparición pública el 7 de enero de 1965, con la toma de la población de Simacota. Luego vendría una serie de acciones que le otorgaron prestigio entre los activistas de izquierda, como el asalto a un tren pagador, que fuera filmado por un periodista mexicano. Pero el momento más brillante en estos años fue cuando el exsacerdote Camilo Torres Restrepo se incorporó al destacamento guerrillero. Camilo había hecho un rápido proceso de radicalización dentro de su perspectiva cristiana, casi tan veloz como su fugaz campaña política de poco menos de seis meses. Con la idea de llegar a amplios sectores de la población, Camilo había creado, en 1965, el Frente Unido (FU), que intentó ser una alianza de oposición al Frente Nacional, pero que en la medida en que se polarizó en torno a la abstención, alejó a los grupos de izquierda que participaban en elecciones para quedar en

\footnotetext{
${ }^{11}$ Aunque ha sufrido varias divisiones, hoy se mantiene como el núcleo más organizado de la izquierda electoral en torno a la carismática figura del senador Jorge Enrique Robledo.

${ }^{12}$ Muchos de estos jóvenes estaban afiliados al Movimiento Revolucionario Libreral (MRL), que al inicio se opuso al Frente Nacional, pero luego se reintegró al liberalismo. Otros venían del comunismo y algunos del radicalizado movimiento estudiantil. Nótese que el ELN fue el único grupo que se fundó en el exterior y que curiosamente tuvo como dirigente máximo por varios años a un español, el cura Manuel Pérez (BRODERICK, 2001). También es importante señalar que fue la guerrilla que más cristianos reclutó, algunos de ellos sacerdores.
} 
manos de los activos del ELN. Con el ingreso de Camilo a la guerrilla a fines de ese año, el FU se debilitó para desaparecer prontamente. Para el ELN como tal, el periodo comprendido entre 1965 y 1970 fue de crecimiento en términos de militancia, a pesar de la prematura muerte de Camilo en su primer combate, en febrero de 1966. Luego vendrá la ofensiva oficial en Anorí (Antioquia), el desmantelamiento de las redes urbanas y los consiguientes consejos de guerra, que casi aniquilan la organización (MEDINA, 1996, 141). Para mediados de los 1970, mientras su máximo dirigente se ausentaba del país, la organización inició un proceso de replanteamiento sobre la concepción foquista. ${ }^{13}$

Por los mismos años en que se gestaba el ELN, y casi desde las mismas bases, surgió el Partido Comunista Marxista Leninista (PC-ML), el otro bastión del maoísmo hasta finales de los años 1970 (VILLARRAGA y PLAZAS, 1995). Con la ruptura sinosoviética, hubo un sector minoritario dentro del PCC y más numeroso dentro de la Juventud Comunista que, al ser expulsado, convocó a todos los marxistas-leninistas a formar un nuevo partido. En julio de 1965, celebraron el “décimo” Congreso, que con este ordinal continuaba la numeración de los correspondientes eventos del PCC, al que buscaban reconstituir. En 1967, consolidaron su brazo armado, el Ejército Popular de Liberación (EPL), el cual pretendió abrir varios focos en varias zonas periféricas del país, pero solo sobrevivió la de la Costa Atlantica. Pero incluso este foco fue sometido a un duro cerco por parte de las fuerzas del orden a fines de los 1960. En el proceso de crear y consolidar el brazo armado, no solo murió la mayoría de sus fundadores, sino que la organización se aisló del conjunto social, al trasladar su dirección al campo. El PC-ML, caracterizado por su defensa ortodoxa del maoísmo hasta 1980, fue expulsando a diversos núcleos que diferían en cuestiones de táctica revolucionaria o de organización, lo que dio origen a varias organizaciones del llamado "campo M-L". ${ }^{14}$ Pero la marca más fuerte del maoísmo fue la rivalidad, a veces armada, con el PCC y su brazo armado.

\footnotetext{
${ }^{13}$ El ELN será tal vez la guerrilla más radical y nunca firmó una tregua con el Estado colombiano, tanto que aún hoy en día -abril de 2015- no ha concretado una negociación para un acuerdo de paz.

${ }^{14}$ Alguna de ellas se transformaría años después en la organización político-militar Partido Revolucionario de los Trabajadores (PRT), que tuvo asiento en la costa norte y se desmovilizó en 1991, luego de intentar fusionarse con el ELN. De hecho, hubo otra fracción maoísta que si se integró por unos años a esta guerrilla, el Movimiento de Izquierda Revolucionaria (MIR), pero muchos de sus integrantes se desmovilizaron a mediados de los años 1990, como veremos en su momento.
} 
Para completar el cuadro de estos años, resta mencionar precisamente el surgimiento como tal de las Fuerzas Armadas Revolucionarias de Colombia (FARC). Después de las vacilantes declaraciones del PCC con relación a la lucha armada, vino la ofensiva estatal contra las llamadas "repúblicas independientes”. La operación contra algunas zonas de "colonización armada", como Marquetalia, presionó la convocatoria de la primera conferencia guerrillera comunista a fines de 1964. En mayo de 1966, definitivamente las autodefensas se transformaron en las FARC. Estas seguirían un modelo militar de autodefensa y de apoyo a la actividad del Partido hasta entrados los años 1980, cuando variarían hacia una táctica más ofensiva de búsqueda del poder. La historia de las FARC fue menos espectacular que la de otros grupos guerrilleros en estos años e incluso la organización estuvo a punto de sucumbir, a causa de algunos fracasos militares. Al contrario de las otras guerrillas colombianas, su base fue siempre más campesina, lo que se reflejó en su inicial plataforma política (PIZARRO, 1995). En este sentido, estuvo lejos del foquismo predominante en los otros grupos armados y más bien se acercó en la práctica a la "guerra popular prolongada" que caracterizó a la experiencia china.

\section{¿La revolución a la vuelta de la esquina? (1970-1981)}

El concierto internacional en este periodo estuvo signado por el fin del crecimiento económico en los países centrales, producto a su vez del incremento de los precios del petróleo, en 1973. En estas condiciones, los Estados de Bienestar europeos entraron en crisis y "las verdades seguras de la era fordista empezaron a desmoronarse" (ELEY, 2003, 402). Esto, sin duda, afectó a la izquierda occidental, especialmente a los partidos socialistas y comunistas, en sus intentos de reformar el capitalismo. El espíritu revolucionario de Mayo del 68 parecía encontrar su confirmación no solo por los efectos sociales negativos de la recesión económica del capitalismo, sino por los avances democráticos en Europa y los triunfos anticoloniales en algunos países de la periferia. Pero la herencia de los años 1960 se fue desvaneciendo por las pugnas entre los distintos modelos de socialismo y la crisis teórica del marxismo, lo que despertó incertidumbre en la izquierda mundial (ANDERSON, 1986). 
En América Latina, la acción política va a estar marcada por la crisis de la democracia, a su vez relacionada con la recesión económica mundial y con el fortalecimiento de dictaduras de extrema derecha. En efecto, el triunfo electoral de Salvador Allende en Chile, en 1970, propuso al conjunto de la izquierda latinoamericana otra vía diferente de la armada para lograr la transformación social. Pero esta propuesta fue violentamente suprimida por el golpe militar dirigido por Augusto Pinochet y el inicio de una "guerra sucia" contra la izquierda, que será replicada por otras dictaduras del Cono Sur. Mientras tanto ocurre un desplazamiento geopolítico en las izquierdas armadas, del Cono Sur a Centroamérica, que apuntalará lo que para muchos constituye la segunda oleada guerrillera en América Latina (MARTI y FIGUEROA, 2006; WICKMANCROWLEY, 1992).

En Colombia, el periodo considerado está enmarcado por la crisis del Frente Nacional y su lento desmonte a partir de 1974. Las elecciones de 1970, acusadas de “fraudulentas” por la oposición, sirvieron para agitar el debate sobre la vía revolucionaria en el seno de la izquierda. Si bien el general Rojas, ahora en su fase populista, mostró el potencial de la movilización de masas, el "fraude" con que se le arrebató este virtual triunfo mostró las limitaciones de la vía electoral (AYALA, 2006). Pero no fueron las guerrillas rurales creadas en la década pasada las que recogieron esta lección, sino el Movimiento 19 de Abril (M-19) -denominado así precisamente en conmemoración de aquel lance electoral. Se trataba de un grupo con rasgos similares a los de Montoneros y Tupamaros, que tuvo notable presencia urbana y manifestó una ideología nacionalista que concentró la atención pública, entre otras razones por la novedad propagandística y mediática que presentó. Nos referimos no solo a las acciones cotidianas de incautar alimentos para dárselos a los pobres, sino especialmente al robo de más de 1.500 armas de una guarnición militar altamente custiodiada en enero de 1979. Los militares, heridos en su orgullo, desataron una brutal persecusión, deteniendo a cerca de 300 miltantes del M-19, además de muchos activistas sociales que simpatizaban con este movimiento. Cuando se iba a librar el consejo de guerra en su contra, la organización guerrillera hizó una toma de rehenes diplomáticos -entre ellos el de Estados Unidos y el nuncio del Vaticano- en febrero de 1980, toma que se prolongó por varios meses. Aunque no 
lograron el objetivo de liberar a sus militantes, sí se hicieron a unos dólares y, sobre todo, posicionaron ampliamente el mensaje de un "diálogo nacional” para superar el conflicto armado (ARCHILA, 2003, 292).

Como lo hemos señalado en otros escritos, los años 1970 fueron los que mayores indicadores de luchas sociales muestran en la historia colombiana del siglo XX (ARCHILA y otros, 2002). En ellos, hubo una inusitada e impresionante agitación entre campesinos, obreros y estudiantes (MÚNERA, 1998). El auge de la movilización social alimentó a su vez a las izquierdas, aunque con desiguales resultados. Si bien el grueso de la nueva izquierda colombiana seguía sumido en la debilitada opción armada, crecientemente desde las toldas prosoviéticas, maoístas y trotskistas se consideraba la posibilidad de participar en elecciones como una forma de acción política para llegar a las masas. Incluso hubo sorprendentes intentos de unidad, como el propiciado por el PCC y el MOIR en torno a la Unión Nacional de Oposición (UNO) para las elecciones de 1974.

La convergencia de estos grupos ocurrió a pesar de la enemistad pero fue inestable. En efecto, los mutuos sectarismos quebraron este intento unitario y, para 1978, la izquierda electoral colombiana se agrupó en tres bloques con cierta identidad ideológica, fruto, nuevamente, de la alineación internacional: la UNO, controlada por el PCC una vez que el MOIR abandonó la alianza; este último grupo, a su vez, conformó el Frente Unido del Pueblo (FUP), en el que convergieron las fuerzas maoístas que ingresaban a la arena electoral; y se creó además la Unión de Izquierda Obrera y Socialista (UNIOS), una alianza de grupos socialistas y trotskistas, que rápidamente explotó en fracciones. ${ }^{15}$ Ante esta patética división, un sector de intelectuales, agrupados en la revista Alternativa -de la que hicieron parte Gabriel García Márquez, Orlando Fals Borda y Enrique Santos Calderón, entre otros-, lanzó una campaña de firmas para unificar a la izquierda. Aunque fracasó en lo inmediato, logró conformar una expresión democrática

\footnotetext{
${ }^{15}$ El trotskismo, con gran liderazgo intelectual, llegó a tener influencia en el mundo universitario, sindical y aun en los inicios del movimiento campesino de los 1970 (GARCíA, 2009). Pero, al igual que el maoísmo, se caracterizó por gran pugnacidad interna y sucesivas divisiones, que generaron una estela de siglas bajo la sombra tutelar de León Trotsky y Rosa Luxemburg.
} 
de corta duración, conocida como "Firmes", que vinculó a parte de la intelectualidad de izquierda no afiliada a expresiones partidistas. ${ }^{16}$

Mientras tanto, el fin del Frente Nacional y su lento desmonte despertaban en los colombianos expectativas de apertura democrática, especialmente porque en 1974 subió al poder Alfonso López Michelsen, personaje que arrastraba una cierta imagen progresista por su supuesto pasado rebelde en el MRL y por ser hijo del presidente más reformista de la historia colombiana, Alfonso López Pumarejo. Pero rápidamente quedó claro su verdadero talante político al rechazar airadamente demandas populares y reprimir las protestas sociales. Los ánimos populares se desbordaron además por el incremento del costo de vida y desembocaron en la realización del masivo Paro Cívico Nacional del 14 de septiembre de 1977. A pesar de su indudable magnitud, este evento fue interpretado en forma desproporcionada, tanto por la izquierda como por la derecha. Unos pensaban que la insurrección de masas estaba a la vuelta de la esquina y los otros hicieron lo imposible para sofocarla (MEDINA, 2014, 89). Así, el siguiente gobernante, Julio César Turbay (1978-1982), a un mes de inaugurado su mandato, expidió el Estatuto de Seguridad -hijo de la doctrina militarista del mismo nombre-, que recortaba significativamente las libertades democráticas. ${ }^{17}$ Para gran parte de la izquierda colombiana -que hacía eco de lo ocurrido en América Latina-, los nuevos signos eran una expresión de la represión de derecha, a la que había que responder con una nueva guerra de guerrillas. De nuevo, las expectativas de apertura democrática eran sofocadas bajo el ruido de las armas.

\section{Encuentro con el país (1982-1990)}

En 1981, sube al poder en los Estados Unidos Ronald Reagan, quien además de reafirmar el modelo neoliberal implementado por la Thatcher en Inglaterra Ileva la Guerra

\footnotetext{
${ }^{16}$ Firmes se disolvió en una alianza con el PCC a comienzos de los 1980. Al igual que la revista Alternativa, tuvo influencia del M-19.

${ }^{17}$ Aunque Turbay ya había proclamado el Estatuto de Seguridad pocos días antes del primer aniversario del Paro Cívico de 1977, el torpe asesinato del ex ministro de gobierno, Rafael Pardo Buelvas, por parte de un comando urbano llamado Autodefensa Obrera (ADO), le sirvió al mandatario para justificar la represión. Este fue un pequeño grupo que quedó diezmado después de esa torpeza y lo que restaba se desmovilizó en 1985.
} 

limitaciones, por lo que necesitaba urgentes reformas para sobrevivir (HOBSBAWM, 1994). En este contexto, Mihail Gorvachov asciende a la máxima posición en el URSS, en 1985, y centra su programa reformista en la "perestroika" -reestructuración económica y política- y el "glasnost” -transparencia en la información. Así, el descontento larvado por años en la "cortina de hierro" sale a flote y, por fortuna, no encuentra la vieja respuesta represiva soviética. Como un nuevo dominó -ahora de otro signo-, uno tras otro, los países satélites se van alejando del control soviético y van deponiendo a sus gobiernos comunistas. A fines de 1989, cae el simbólico muro de Berlín, que partía en dos a Alemania y en general a Europa. Dos años después desaparecería la propia Unión Soviética, desmembrada por los apetitos nacionalistas en una serie de países que ni siquiera podrían federarse (ELEY, 2003, cap. 25). Mientras tanto, en la lejana China, bajo la dirección de Deng Xiao Ping, se consolidaba el viraje pragmático hacia la economía capitalista, sin producir ninguna liberalización en el plano político (HOBSBAWM, 1994, 486-487).

Las izquierdas latinoamericanas no se quedaron contemplando el derrumbe del "socialismo real". Se involucraron crecientemente en la lucha contra las dictaduras y por el retorno a la democracia. Aunque no cosecharon inmediatamente triunfos electorales, se comprometieron cada vez más decididamente en la ampliación de la ciudadanía para los habitantes de la región. Los vientos democráticos alcanzaron también a la izquierda guerrillera, que en muchas partes retomó la crítica a las armas. Luego del triunfo sandinista de 1979 en Nicaragua, el escenario privilegiado de la lucha era Centroamérica, especialmente El Salvador y en menor medida Guatemala. La derrota electoral del sandinismo y los reveses de las fuerzas insurgentes en los otros países, las llevaría a procesos de negociación para deponer las armas (MARTI y FIGUEROA, 2006; WICKMANCROWLEY, 1992).

En Colombia también la izquierda asumió el reto democrático al propiciar diálogos de paz con el gobierno de Belisario Betancur (1982-1986), que se concretaron en 1984 con 
inestables treguas, primero con las FARC y luego con el M-19 y el EPL. Este gobierno sufrió el mayor impacto de la crisis latinoamericana de la deuda, por lo que al principio adelantó una política económica proteccionista, que no resistió dos años, para luego ingresar en la corriente de reestructuración impulsada por la banca multilateral. Paralelamente, Betancur impulsó una reforma política, especialmente la descentralización presupuestal y la elección popular de alcaldes. Mientras tanto algunas de las agrupaciones de izquierda describieron trayectorias sorprendentes, en las que se alejaron de viejos dogmatismos y alineamientos internacionales para acercarse a las gentes de carne y hueso. Era una forma creativa de responder a la creciente crisis de las izquierdas mundiales.

Al mismo tiempo, la agitación social en Colombia reinició un nuevo ciclo con los llamados movimientos cívicos y regionales, en grandes jornadas que paralizaron, ya no solo barrios o ciudades intermedias, sino amplias regiones, como ocurrió en el segundo lustro de los 1980. Es también ésta una época de anhelos unitarios, que se plasmaron en la creación de la Organización Nacional Indígena de Colombia (ONIC), en 1982, la Central Unitaria de Trabajadores (CUT), en 1986, y el reagrupamiento de organizaciones campesinas, un año después (MÚNERA, 1998, 458-469).

Pero la consecución de la paz no fue posible, porque tanto el Estado como las guerrillas mantenían agendas ocultas que seguían apostando a la guerra. Además, los endebles acuerdos fueron torpedeados desde distintos flancos. Sin haber cumplido un año, la tregua con las organizaciones armadas ya se había roto, hecho que fue consumado con la cruenta toma del Palacio de Justicia por un comando del M-19 y la brutal recuperación oficial del 5 y 6 de noviembre de 1985. Pocos días después, caía asesinado en las calles de Bogotá el vocero del EPL, Oscar William Calvo. Por su parte, las FARC mantuvieron los acuerdos de paz por dos años más. La agrupación política impulsada por la guerrilla para ingresar a los ámbitos públicos, la Unión Patriótica (UP), fue rápidamente diezmada, en lo que ha sido catalogado como un "genocidio político". ${ }^{18}$

\footnotetext{
${ }^{18}$ No se dispone de cifras exactas de los muertos de la UP, salvo la generalizada expresión de que son más de 3.500 (ARCHILA, 2003, 122). En una tesis para optar al título de Historiadora, la estudiante Johana Trujillo (2005) logra documentar 1.095 casos entre 1986 y 1990. La mayoría de las víctimas corresponden a zonas donde había presencia histórica de las FARC y el aumento de asesinatos de la UP se produce en coyunturas electorales.
} 
Algo similar ocurrió con los frentes políticos de otras guerrillas como A Luchar, impulsado por el ELN y sectores sindicales, y el Frente Popular, creado por el EPL. ${ }^{19}$ De este modo, para 1987 las organizaciones armadas que habían pactado tregua con el Estado estaban de nuevo en la guerra, con una importante novedad orgánica -aprendida de la lucha centroamericana: una coordinadora guerrillera que agrupaba a todas las organizaciones armadas, salvo a las FARC, en un principio. Éstas finalmente ingresaron en 1987, una vez rota su tregua, e hicieron que a las siglas de la coordinadora se le añadiera el nombre del Libertador: Coordinadora Guerrillera Simón Bolívar (CGSB). ${ }^{20}$

Para este momento, el conflicto colombiano se había fragmentado en múltiples actores. Además del histórico enfrentamiento entre Estado e insurgencia, aparecieron sectores paramilitares, ligados en forma creciente a la actividad del narcotráfico. En 1982, a raíz del secuestro por el M-19 de una integrante de un clan de narcotraficantes antioqueños, estos crearon el grupo Muerte a Secuestradores (MAS), que no solo consiguió el objetivo de liberar a la plagiada sino que además inauguró una nueva forma de acción contrainsurgente. En efecto, en zonas de antiguo conflicto armado aparecieron "autodefensas", que decían oponerse a los desmanes y prácticas extorsivas de la insurgencia. Tales agrupaciones contaron con permisividad, cuando no con apoyo abierto, de elites y autoridades civiles y militares de dichas regiones (ROMERO, 2003). Con mayor frecuencia e intensidad acudieron al narcotráfico como fuente de financiación. Este es el trasfondo de la "guerra sucia" que la derecha civil, militar y paramilitar lanzó contra la UP y en general contra los activistas sociales y de izquierda, de la que no se libraron candidatos presidenciales progresistas, como Jaime Pardo Leal, en 1987, Luis Carlos Galán, en 1989, Bernardo Jaramillo Ossa y Carlos Pizarro, ambos a inicios de 1990.

Con todo, la semilla de la paz o, mejor, de la búsqueda de una salida política del conflicto armado, fructificó a finales del decenio, cuando el M-19 expresó su voluntad de

\footnotetext{
19 En realidad, lo que se presenta desde mitad de los 1980 es una violencia generalizada contra militantes de izquierda y dirigentes sociales campesinos, indígenas, mujeres y sindicalistas como una forma de impedir el indudable ascenso de la movilización social y una expresión del trágico anticomunismo de nuestras elites (ARCHILA y otros, 2011).

20 Pero al contrario de la experiencia centroamericana, en Colombia la CGSB duró poco tiempo, pues algunas guerrillas negociaron la paz y otras, como el ELN y las FARC, después de un intento de negociación conjunta entre 1991 y 1992, reemprendieron la guerra, pero cada una por su cuenta y a veces enfrentadas entre ellas.
} 
desmovilizarse y actuar como un grupo político legal y presionó a favor de la celebración de una Asamblea Constituyente, encargada de formular un nuevo pacto social y político en Colombia. La iniciativa fue apoyada por sectores de la izquierda legal y por algunos movimientos sociales, con los cuales se conformó la Alianza Democrática (AD-M19). También fue imitada por otros destacamentos de alzados en armas del extinto maoísmo, como el PRT y el EPL, del que se desmovilizó el grueso de su militancia para conformar un nuevo grupo, Esperanza, Paz y Libertad -los “esperanzados”21-, así como por la guerrilla indigenista, el Movimiento Armado Quintín Lame (MAQL). El resto de organizaciones armadas no participó en la Constituyente, pero dejó abierta la puerta para futuras negociaciones con el Estado, a pesar del ataque que recibieron las FARC en la sede de su comandancia el mismo día en que se votaba la conformación de dicha Asamblea. De nuevo, la paz y la guerra se presentaban simultáneamente, dejando serios interrogantes sobre el futuro del país y de su democracia.

\section{Crisis de las izquierdas (1991-1999)}

La caída del "socialismo real” se ratificó con la disolución de la Unión Soviética, en 1991, y el fin de la Guerra Fría. El capitalismo en su fase tardía, claramente neoliberal, se impone por casi todo el orbe, y con especial ortodoxia en los antiguos países socialistas, tanto que algunos de sus áulicos se apresuran a celebrar el "fin de la Historia". Sin embargo, el triunfo del liberalismo económico no significó el afianzamiento de su contraparte política, la democracia liberal. Los Estados Unidos surgían claramente como la gran potencia enfrentada, ya no a un rival similar, sino a múltiples focos de resistencia con identidades diversas que iban desde la lucha contra el neoliberalismo hasta la oposición a Occidente y su tradición judeo-cristiana (HOBSBAWM, 1994).

Ante estos eventos, la izquierda mundial comunista y socialista no actuó con la rapidez y contundencia de épocas pasadas. El abandono de la tradición revolucionaria y

\footnotetext{
${ }^{21}$ El EPL, y por detrás el PC-ML, tuvo un giro sorprendente a principios de los 1980, cuando no solo abandonó el maoísmo, al que consideró una nueva desviación ideológica, sino que rompió con el aislacionismo que venía practicando para acercarse a las bases sociales. Este giro político le produjo réditos en las zonas en donde tenía presencia, pero lo hizo entrar en roces con otras organizaciones de izquierda, especialmente las FARC, con las que tenía una vieja rivalidad (ARCHILA y otros, 2011, 152-198).
} 

tradición marxista-leninista. En efecto, los partidos vanguardistas de cuadros son duramente criticados y solo se aceptan formaciones electorales de masas que parecen desempeñar un papel subordinado ante las movilizaciones sociales. La centralidad y el universalismo del proletariado se relegan al pasado e irrumpen múltiples identidades que se alejan del paradigma de las clases (ELEY, 2003, caps. 26-27). Así, se dará un nuevo ciclo de luchas globales al cambio de siglo, aunque este se inaugura con el levantamiento zapatista, en 1994, contra la vigencia del Tratado de Libre Comercio (TLC) norteamericano (SEOANE y TADDEI, 2001, 105-129; RODRÍGUEZ, 2002).

En América Latina la implantación del neoliberalismo toma también de sorpresa a las izquierdas partidistas, que se ven relegadas por la irrupción de otros movimientos sociales. Aquí, se observa igualmente la mutación de las tradiciones revolucionarias en una "nueva" izquierda no marxista ni siquiera socialista, muy integrada a los movimientos sociales y proclive a reformas revolucionarias. Aunque durante este decenio los mandatarios son predominantemente de centro-derecha, la izquierda se asoma al poder desde prácticas exitosas de gobierno local, en donde resalta el impulso de la democracia participativa en dimensiones como la elaboración de los presupuestos locales y regionales (HARNECKER, 2000). La lucha armada va desapareciendo como medio de lucha de la izquierda latinoamericana, que cada vez más se compromete en la construcción de la utopía de una democrática radical.

En este periodo, Colombia estrenó nueva Constitución -expedida en 1991-, no exenta de contradicciones, pues mientras consagró formalmente el Estado social de derecho y el pluralismo cultural y étnico, abrió las puertas al neoliberalismo, y definitivamente no frenó una guerra que ha escalado en intensidad mientras se degrada, hasta provocar una crisis humanitaria sin parangón en el continente. Por tanto, naufragaban las esperanzas de una salida política del conflicto armado, plasmadas en la desmovilización de los contingentes guerrilleros ya señalados en el apartado anterior, a los que se sumó, en 1994, una disidencia del ELN de raíces maoístas, conocida como 

matizadas por efímeros intentos de negociación que parecieron fructificar en 1999 con las FARC, tras el despeje de cinco municipios en la región sur del país, el Caguán, casi tan grande como Suiza. No ocurrió igual con el ELN, más presto a dialogar con la sociedad civil que con los gobiernos de turno. Sucesivos errores militares de esta última guerrilla impidieron la realización pública de una Convención Nacional, y cuando ésta se concertó en el cambio de siglo, las comunidades del sur de Bolívar, atizadas por los paramilitares, se opusieron rotundamente.

Pero los diálogos con las FARC estaban destinados al fracaso, no solo porque se desarrollaban en medio de la guerra, manteniendo cada parte una agenda oculta para fortalecerse militarmente, sino porque se agigantaba el paramilitarismo, alimentado ahora por entes de autodefensa legalizados como cooperativas "Convivir", por los lazos con sectores de las fuerzas armadas y las elites regionales, y especialmente por la financiación del narcotráfico, que salpicaba también a la insurgencia en forma creciente. El deterioro en la vigencia de los derechos humanos, a pesar de la flamante Constitución, y el aumento vertiginoso del desplazamiento forzado desde las áreas de conflicto armado y que al cambio de siglo llegaba a cubrir a dos millones de colombianos para subir a casi seis millones en $2014^{23}$, ilustran la crisis humanitaria en que se vio sumido el país.

En estas condiciones, se hizo más evidente el desconcierto de la izquierda partidista, de la que no escaparon las recientes formaciones políticas resultantes de la desmovilización de fuerzas guerrilleras. Así, la UP y la AD-M19 prácticamente desparecieron del mapa político en los 1990, para no hablar de los partidos de izquierda, que subsistían solo como siglas de un pasado que parecía remoto. Para 1998, la izquierda partidista no obtuvo ningún parlamentario, si se exceptúa a un líder sindical militante del MOIR, que logró obtener una curul por su figuración social. A la caída del socialismo real y

\footnotetext{
${ }^{22}$ Esta disidencia proviene mayoritariamente del MIR, que se había fusionado a fines de los 1980 con el ELN, como ya señalábamos en nota anterior.

${ }^{23}$ Cifras de la ONG que hace ese seguimiento (disponible en: $\langle w w w . c o d h e s . o r g\rangle$. Acceso en 1 de abril de 2015).
} 
la crisis global del marxismo se le agregó en Colombia la persistente violencia, que amilanó toda expresión legal de izquierda, dejando el espacio a los grupos armados, que cada vez más negaban en la práctica los ideales libertarios que decían iluminarlos.

Esto se hizo evidente en forma dramática en el enfrentamiento armado entre desmovilizados del EPL y un reducto de esta guerrilla que permaneció en armas. Este último se alió con las FARC, que buscaba controlar sectores sindicales y sobre todo territorios con clara presencia de los "esperanzados", especialmente en la región de Urabá. Revivió así la vieja enemistad entre las guerrillas de inspiración soviética y maoísta, aunque estos orígenes ahora parecieran cosas del pasado. Los "esperanzados”, a su vez conformaron "comandos populares" de defensa y buscaron apoyo en las fuerzas del orden y aun en sectores paramilitares. En consecuencia, se produjo una violencia fratricida salpicada de escalofriantes masacres de lado y lado, que terminó con la expulsión de las FARC del Urabá y la desaparición de la UP en la región a fines de este decenio (ARCHILA y otros, 2011, 175-185).

Pero también en Colombia la resistencia social tomó el relevo de la acción política y militar. La agitación social en los años del final del siglo incursionó en forma creciente en terrenos directamente políticos (ARCHILA y otros, 2002). La movilización ya no era solamente por carencias materiales, sino también por la disputa en torno a planes de desarrollo y políticas estatales y la exigibilidad de derechos al Estado. Esto va propiciando amplias convergencias sociales y políticas que redundarán en nuevos procesos organizativos de las izquierdas, como veremos a continuación.

\section{Hacia la reconstrucción (2000-2010)}

El comienzo del nuevo siglo acentúa las tendencias observadas en el decenio anterior. La unipolaridad y la hegemonía de los Estados Unidos sufren un devastador ataque terrorista el 11 de septiembre de 2001. Es claro que, así como el imperio no tiene un solo centro, sus enemigos tampoco se ubican en un espacio definido (HARDT y NEGRI, 2002). Por su parte, el modelo neoliberal muestra evidentes signos de agotamiento en 
medio de la recesión mundial de finales del siglo XX y es enfrentado también globalmente por los movimientos sociales, como ya mencionamos (SEOANE y TADDEI, 2001, 105-129).

En América Latina, la crisis del neoliberalismo es más pronunciada, especialmente por sus pésimos resultados sociales (OCAMPO, 2004, 781-782). Por todas partes de la región, las masas de desempleados, obreros, campesinos, indígenas, estudiantes, amas de casa y pobladores urbanos, entre otros, se movilizan contra la globalización económica y presionan por cambios políticos, provocando con ello un giro hacia la izquierda. ${ }^{24}$

Estos avances electorales en el continente fueron resultado no solo de nuevas estrategias políticas de la izquierda, sino especialmente de las nuevas formas de movilización social que desbordan a estructuras partidistas (RODRÍGUEZ y otros, 2005, MARTí y FIGUEROA, 2006). Además de demandas particulares, muchos actores sociales enarbolan banderas de resistencia a la globalización económica y presionan por una mayor autonomía nacional en el manejo de los recursos naturales, mientras reanudan las exigencias de ampliación de la democracia. Igualmente, se presentan convergencias transnacionales, como la encarnada por los Foros Sociales Mundiales inaugurados en Porto Alegre, Brasil, en 2001 (SEOANE y TADDEI, 2001).

En medio de este panorama continental, Colombia aparece como una excepción no solo por el autoritarismo de derecha, encarnado en el prolongado régimen de Álvaro

\footnotetext{
${ }^{24}$ En un libro de balance sobre las recientes izquierdas latinoamericanas las llaman descriptivamente "nueva izquierda" y las caracterizan a partir de cinco rasgos: pluralidad de formas organizativas y de objetivos, ampliación de las bases sociales y agendas políticas, poner la sociedad civil como espacio principal de su acción política, buscar reformas revolucionarias y otorgar centralidad a la democracia. Estos rasgos los resumen en dos de mucha actualidad: la búsqueda de alternativas al neoliberalismo y la democratización de la sociedad (RODRíGUEZ y otros, 2005, 31-37). Años antes, Jorge Castañeda (1994, 25-26) la contrastaba con la derecha por defender el cambio sobre la continuidad, la democracia y los derechos humanos sobre la seguridad nacional, la identidad y la soberanía nacional sobre la integración económica, la justicia social sobre el desempeño económico, la distribución del ingreso sobre el funcionamiento del mercado, reducir las desigualdades sobre la competitividad, el gasto social sobre el control de la inflación y la necesidad del gasto sobre el saneamiento de las finanzas gubernamentales. En 2006, el entonces candidato presidencial colombiano de la izquierda, Carlos Gaviria Díaz, terció en el debate y señaló: "Entre la vieja izquierda y la actual hay una diferencia clara, y es el cambio de utopía: mientras la izquierda clásica buscaba la sociedad sin clases [... ] la moderna lo que busca es una sociedad democrática posible" (El Espectador, 23-29 de abril de 2006, 14-A). En este texto, dejamos de lado la distinción, de sabor mediático, entre izquierdas latinoamericanas moderadas y radicales, pues es difícil hacer una tajante diferenciación, ya que comparten idearios y prácticas, por ejemplo el extractivismo, a pesar de las supuestas diferencias discursivas.
} 
Uribe Vélez (2002-2010), sino asimismo por el creciente alineamiento que este mandatario tuvo con el gobierno de George W. Bush y que provocó marcadas tensiones con los países vecinos. El fracaso de las negociaciones de paz con las FARC, a inicios de 2002, inclinó a la opinión pública, por primera vez en veinte años, a la opción guerrera. La política de "Seguridad Democrática" de Uribe Vélez aplicó mano dura a la insurgencia, mientras extendía la mano enguantada a los paramilitares. Estos, en un proceso de desmonte parcial de sus estructuras militares, conservan las económicas y políticas, mientras ocultan la verdad sobre las atrocidades cometidas. El narcotráfico, a pesar de las ostentosas campañas oficiales para derrotarlo con el empleo de costosas fumigaciones aéreas, sigue siendo una actividad altamente rentable que alimenta a todos los actores armados, sin desconocer la irrigación que hace al conjunto de la sociedad. Las FARC, por su parte, hicieron un repliegue táctico sin que hubiera signos de una derrota, a pesar de haber sufrido golpes duros en sus estructuras militares. EI ELN, por su parte, entabló tibios diálogos con el gobierno, apelando a una mayor participación de la sociedad civil, mientras buscaba afanosamente formas más rentables de financiamiento, por lo que chocó a veces con las FARC.

Esta coyuntura política, aunque favoreció al bloque uribista, fue también una oportunidad de crecimiento y unidad para la izquierda democrática. La dispersión e invisibilidad que la caracterizó durante el periodo anterior, empezó a ser superada en 1999, con la creación del Frente Social y Político, por iniciativa de la CUT. Fruto de la polarización creciente y de frustradas reformas políticas, las distintas fuerzas de la izquierda social y política convergieron en el Polo Democrático Alternativo (PDA), lo que posibilitó algunos avances electorales significativos, como la conquista, en 2003, de la alcaldía de Bogotá, evento que se repitió en 2007 y en 2011. Estas tendencias se ratificaron con la votación parlamentaria de la izquierda lograda en 2006 , cercana al $12 \%$, y especialmente con la que respaldó al candidato presidencial Carlos Gaviria, quien obtuvo un honroso $22 \%$ y logró la segunda votación nacional después de la del presidente reelecto. ${ }^{25}$ Claro que no hay que llamar a triunfalismos, pues parte de esta votación no fue

\footnotetext{
${ }^{25}$ Históricamente, es el segundo resultado electoral de la izquierda colombiana. El primero fue la votación por la AD-M19 para la constituyente de 1991, que fue del 27\% (ARCHILA, 2003, 296).
} 
a favor de la izquierda, sino en contra de Uribe Vélez. ${ }^{26}$ Además, la anhelada unidad en la pluralidad de la izquierda parece resquebrajarse por motivos que van desde viejas contradicciones ideológicas hasta disfrazados apetitos personales de poder, pasando por la pervivencia interna de prácticas poco democráticas y hasta por la aparición de fenómenos de abierta corrupción. ${ }^{27}$ Por esto, el PDA se ha dividido dando origen a nuevos grupos electorales que se disputan entre ellos la pequeña proporción de población, especialmente urbana, que vota por la izquierda.

Ante este crítico panorama, en Colombia, como en otras partes de América Latina, surgen movimientos sociopolíticos ${ }^{28}$, que renuevan desde abajo la agenda de una izquierda que lucha por la libertad y la igualdad, enarbolando el respeto a la diferencia. Parte de su agenda es el impulso a la negociación política del conflicto armado que parece abrirse camino con los recientes diálogos entre las FARC y el gobierno de Juan Manuel Santos (2010-2018) en La Habana y los que se insinúan con el ELN. ${ }^{29}$ Aunque el futuro no está garantizado, hay signos esperanzadores de que también Colombia transita, a su manera, hacia una utopía posible.

\footnotetext{
${ }^{26}$ De hecho, en 2010 y 2014 el voto por un candidato presidencial de izquierda volvió a ser cercano al 10\%.

${ }_{27}$ Como el ocurrido en Bogotá en la pasada alcaldía de Samuel Moreno Díaz (2007-2010), nieto del general Rojas Pinilla.

${ }^{28}$ Nos referimos a agrupaciones como la Marcha Patriótica y el Congreso de los Pueblos, que recogen diversos movimientos sociales y políticos, en una acción que trasciende lo electoral, sin despreciarlo.

${ }^{29}$ Santos, nacido de la entraña del gobierno de Uribe Vélez, se ha apartado de éste solo en el tema de la paz, pues en los otros sigue la agenda neoliberal de su antecesor. Pero basta esta ruptura para que el uribismo duro le haya declarado una oposición, que, como suele ocurrir en Colombia, también combina todas las formas de lucha.
} 


\section{Referencias}

ANDERSON, Perry. Tras las huellas del materialismo histórico. México: Siglo XXI, 1986.

ARCHILA, Mauricio. Cultura e identidad obrera: Colombia 1910-1945. Bogotá: Cinep, 1992.

ARCHILA, Mauricio. Idas y venidas, vueltas y revueltas, protestas sociales en Colombia 19581990. Bogotá: Cinep/Icanh, 2003.

ARCHILA, Mauricio. La izquierda hoy: reflexiones sobre su identidad, In: ESTRADA, Jairo (compilador). Izquierda y socialismo en América Latina. Bogotá: Universidad Nacional, 2008.

ARCHILA, Mauricio y otros. 25 años de luchas sociales en Colombia. Bogotá: Cinep, 2002.

ARCHILA, Mauricio y otros. Una historia inconclusa: izquierdas políticas y sociales en Colombia. Bogotá: Cinep, 2009.

ARCHILA, Mauricio y otros. Violencia contra el sindicalismo, 1984-2010. Bogotá: Cinep, 2011.

AYALA, César. El populismo atrapado, la memoria y el miedo. Medellín: La Carreta, 2006.

BOBBIO, Norberto. Derecha e izquierda. Razones y significados de una distinción política, Madrid: Taurus, 1995.

BRODERICK, Joe. El guerrillero invisible. Bogotá: Intermedio, 2001.

CALLINICOS, Alex. Igualdad. Madrid: Siglo XXI, 2003.

CASTAÑEDA, Jorge. La utopía desarmada. Intrigas, dilemas y promesas de la izquierda en América Latina. Bogotá: Tercer Mundo, 1994.

DEBRAY, Regís. La crítica a las armas. México: Siglo XXI, 1975.

El Espectador, 23-29 de abril de 2006, 14-A.

ELEY, Geoff, Un mundo que ganar. Historia de la izquierda en Europa, 1850-2000. Barcelona: Crítica, 2003.

GARCÍA, Martha Cecilia. El presente es de lucha el futuro socialista, In: ARCHILA, Mauricio y otros. Una historia inconclusa: izquierdas políticas y sociales en Colombia. Bogotá: Cinep, 2009. 
HARDT, Michael y NEGRI, Antonio. Imperio. Buenos Aires: Paidos, 2002.

HARNECKER, Marta. La izquierda en el umbral del siglo XX. Madrid: Siglo XXI, 2000.

HARTLYN, Jonathan. La política del régimen de coalición. Bogotá: Tercer Mundo/Uniandes, 1993.

HOBSBAWM, Eric J. The Age of Extremes. Nueva York: Pantheon, 1994.

KAYE, Harvey J. Los historiadores marxistas británicos. Zaragoza: Prensas Universitarias, 1989.

MARTí, Salvador y FIGUEROA, Carlos. La izquierda revolucionaria en Centro América. Madrid: Cátedra, 2006.

MEDINA, Carlos. ELN: una historia contada a dos voces. Bogotá: Rodríguez Quito, 1996.

MEDINA, Medófilo. Historia del Partido Comunista de Colombia. Bogotá: Ceis, 1980.

MEDINA, Medófilo. El rompecabezas de la paz. Medellín: La Carreta, 2014.

MOLINA, Gerardo. Las ideas socialistas en Colombia. Bogotá: Tercer Mundo, 1987.

MÚNERA, Leopoldo. Rupturas y continuidades: Poder y movimiento popular en Colombia, 1968-1988. Bogotá: Universidad Nacional/lepri/Cerec, 1998.

OCAMPO, José Antonio. La América Latina y la economía mundial en el largo siglo XX, In: Trimestre Económico. Vol. LXXI, no. 284, México, Fondo de Cultura Económica, 2004, 725786.

PIZARRO, Eduardo. Insurgencia sin revolución. Bogotá: Iepri/Tercer Mundo, 1995.

RODRÍGUEZ, César y otros (editores). La nueva izquierda en América Latina. Bogotá: Norma, 2005.

RODRÍGUEZ, Octavio. Izquierdas e izquierdismo. México: Siglo XXI, 2002.

ROMERO, Mauricio. Paramilitares y Autodefensas, 1982-2003. Bogotá: lepri/Planeta. 2003.

SEOANE, José y TADDEI, Emilio (compiladores). Resistencias mundiales (de Seattle a Porto Alegre). Buenos Aires: CLACSO, 2001. 
TRUJILLO, Johana. Democracia, elecciones y genocidio: el caso de la UP.. Bogotá: Universidad Nacional de Colombia, 2005 (Trabajo de grado en Historia).

VILLARRAGA, Alvaro y PLAZAS, Nelson. Para reconstruir los sueños (una historia del EPL). Bogotá: Progresar, 1995.

VOLPI, Jorge. La imaginación al poder. México: Era, 2001.

WICKMAN-CROWLEY, Timothy Patrick. Guerrillas and Revolution in Latin America. Princeton: Princeton University, 1992. 